\title{
Gender and distributional preferences: Experimental evidence from India
}

\author{
Smriti Sharma* \\ UNU-WIDER, Katajanokanlaituri 6B, FI-00160 Helsinki, Finland
}

\section{A R T I C L E I N F O}

\section{Article history:}

Received 16 February 2015

Received in revised form 29 June 2015

Accepted 7 August 2015

Available online 10 August 2015

\section{JEL Classification:}

C91

D63

J16

053

PsycINFO classification:

3020

2300

\section{Keywords:}

Gender

Distributive justice

Laboratory experiment

India

\begin{abstract}
A B S T R A C T
We conduct a lab experiment to assess whether gender of dictators and recipients, and distributional preferences affect allocations in a modified dictator game where both parties perform a cognitive task and the resulting pie to be split is the sum of both parties' earnings. Our key results are first, while on average all dictators keep more than their earned share of the pie, they display some respect for merit as the shares appropriated are correlated with their relative earnings. Second, male dictators appropriate a greater share of the pie than females and more is taken from known gender (male) recipients. Finally, most dictators can be classified as egalitarian, meritocratic or selfish. They invoke these fairness views in a situation-specific manner depending on their relative earning status and reveal self-serving biases.

(c) 2015 The Author. Published by Elsevier B.V. This is an open access article under the CC BYNC-ND license (http://creativecommons.org/licenses/by-nc-nd/4.0/).
\end{abstract}

\section{Introduction and background}

Fairness principles have been invoked to explain the observed departures from game-theoretic predictions of payoffmaximization in a variety of experimental games in the lab and field. Fehr and Schmidt (1999) state, "by now we have substantial evidence suggesting that fairness motives affect the behavior of many people" (p. 817). However, there remains considerable heterogeneity in views about fairness and what constitutes a just outcome in different contexts (see Konow (2003) for an analysis of positive and normative theories of distributive justice).

In this paper, we use a modified version of a dictator game with a production stage preceding the distribution stage, to experimentally examine the effect of two broad factors on the allocation choices of dictators, (a) distributional preferences, and (b) gender. In our lab experiment, following Konow (2000) and Frohlich, Oppenheimer, and Kurki (2004), both subjects in the pair are assigned a cognitive task to be completed individually, without prior knowledge of their role as dictator or recipient. The endowment to be allocated is the sum of performance-based earnings of both subjects. The dictator decides

\footnotetext{
* Tel.: +358465231395.

E-mail address: smriti@wider.unu.edu
} 
how much of the endowment to keep for herself after learning about her and the paired recipient's earnings and gender. Since we have multiple types of pairs with dictators and recipients earning either equally or unequally, we use that variation to discuss motivations for distributive behavior. Further, since we observe the gender of the dictator and also convey information about the recipient's gender to the dictator, we have scenarios where dictators are matched with recipients whose gender is known (either male or female) or the case where they have no information about the gender identity of the paired recipient. This allows us to identify differences between male and female dictators based on knowledge of recipient gender.

This paper builds upon and adds to the existing literature on two major fronts. Earned endowments highlight the pluralism of fairness principles and that is the first area our paper speaks to. There are three prominent fairness principles discussed in the literature. First, strict egalitarianism implies that total income should be distributed equally between the individuals, regardless of how the income was generated. This view is closely related to the inequity-aversion model of Fehr and Schmidt (1999). Second, there are principles that stress the idea of meritocracy by stating that final allocations should be a function of performance. These are of two types. The libertarian principle is one of output equity and posits that people should be held responsible for all factors such as effort and luck affecting their productivity, implying that the fair solution is to give each person what she produces (Nozick, 1974). The other known as liberal egalitarianism or accountability principle is one of input equity and states that people should be held responsible only for variables they can influence such as effort (Konow, 1996). Finally, people can be purely self-interested and only interested in maximizing their own payoffs. Studies find that individuals are heterogeneous regarding these principles (e.g., Cappelen, Hole, Sorensen, \& Tungodden, 2007; Cappelen, Sorensen, \& Tungodden, 2010) and that they endorse principles in a manner that advances their own interests, thereby revealing selfserving biases (e.g., Cappelen, Moene, Sorensen, \& Tungodden, 2013; Rodriguez-Lara \& Moreno-Garrido, 2012).

A second strand of literature relevant to this study is gender. ${ }^{1}$ Evidence on gender differences among dictators is quite mixed and ambiguous, which is largely due to differences in experimental designs (Eckel \& Grossman, 2008). Andreoni and Vesterlund (2001) based on a sample of students from two American universities, demonstrate that altruism among males and females is context-dependent and varies by the price of giving. Gong, Yan, and Yang (2015) find dictator behavior to depend on the cultural context - matrilineal or patriarchal - in rural communities in southwestern China. Similarly, in studies that consider the gender of both parties in the dictator game, the evidence is mixed. Among students at a Swedish university, Dufwenberg and Muren (2006) find no significant gender differences between dictators but they find that more is given to female recipients than to males. In contrast, Ben-Ner, Kong, and Putterman (2004) in their experiment conducted at two American universities, find that rendering information about recipient gender affects decisions of only female dictators. Cadsby, Servetka, and Song (2010) compare the behavior of dictators in same-sex and mixed-sex pairs and find no genderspecific effects among university students in New Zealand.

Importantly, we contribute to the literature that examines the interaction of gender and distributional preferences, using a dictator game with a production stage. Miller and Ubeda (2012) use a within-subject design with changing contexts in their experiment at a British university. They find that most women switch between fairness principles across various contexts while most men adopt only one decision principle, that of selfishness. With Spanish university students, Rodriguez-Lara (2015) uses a between-subject analysis and asks dictators to split the joint endowment according to one of five pre-specified allocation choices. He finds that women's allocation choices depend on their performance relative to the paired participant. Conversely, men's allocation choices are invariant to their relative position. However, unlike the present paper, neither of these papers concerns itself with the gender of the recipient. Further, with the current literature emerging mainly from developed countries, this paper also contributes by providing evidence from a developing country.

The remainder of the paper is organized as follows: Section 2 deals with experimental design. Section 3 reports the descriptive statistics, regressions exploring the correlates of dictator allocations, and discusses motivations and reasons for the dictators' decision-making. Section 4 concludes.

\section{Experiment design}

We use a variant of a dictator game with a production stage. Following Konow (2000), Frohlich et al. (2004), and Cappelen et al. (2007), both players in the pair earn their endowment so that each of them can experience first-hand the effort/skill/ ability required to perform the task. We believe this is helpful in judging respect for another's earned income. In fact, a sizable literature has shown that dictator allocations are a better reflection of initial endowments when those endowments are earned - either by the dictator or the recipient - rather than windfall (e.g., Dasgupta, 2011; Oxoby \& Spraggon, 2008; Ruffle, 1998). The endowment that is then split by the dictator is the sum of both players' earnings from the task.

Upon their arrival at the location of the experiment, subjects were randomly split between two rooms, A and B, such that the number of subjects in both rooms was equal. Each person was handed a slip with a unique identification number and individual names were not used during the experiment. The protocol was as follows: after everyone was seated, instructions for the experiment were handed out and read out aloud by the experimenter, and any questions were answered privately. ${ }^{2}$

\footnotetext{
${ }^{1}$ For excellent reviews of the literature on gender differences in preferences, see Croson and Gneezy (2009), Eckel and Grossman (2008) and Niederle (2014).

2 Appendix A contains the experiment instructions and the decision sheets.
} 


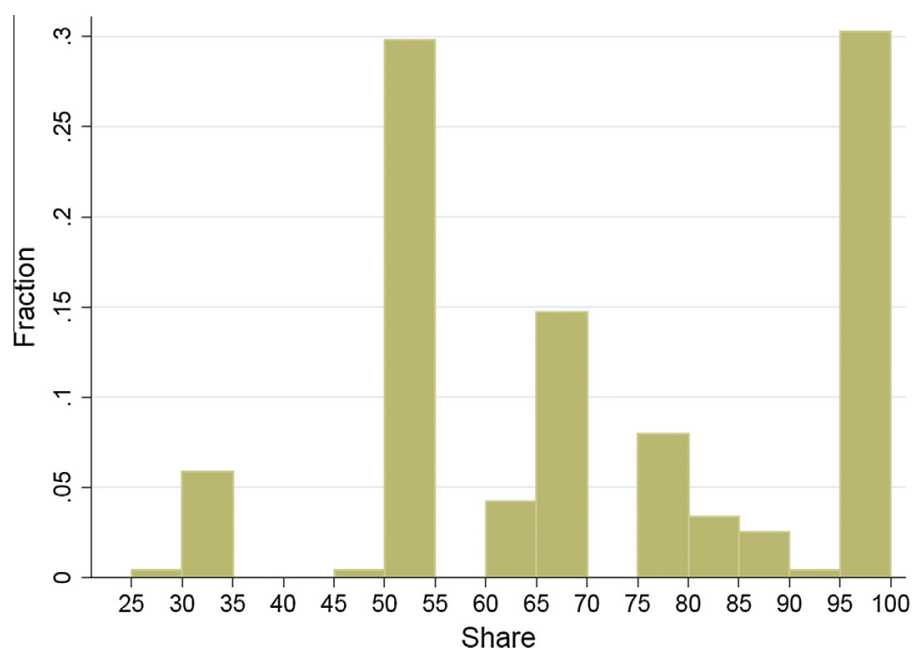

Fig. 1. Distribution of shares appropriated by dictators.

After this, subjects were administered a paper-based, 20-question, multiple-choice, logical reasoning test that lasted 20 min. ${ }^{3}$ Subjects in both rooms had the identical test to solve. Earnings were determined on the basis of the subject's performance relative to others seated in her room. Subjects in each room were ranked in order of their test scores and the top 50\% of subjects earned Rs. 400 ("high" earners) while those in the bottom 50\% earned Rs. 200 ("low" earners).

Next, subjects in room A were randomly matched with those in room B and vice versa. Subjects were handed decision sheets that informed them of their earnings and their randomly matched subject's earnings but not the test scores. ${ }^{4}$ Since the endowment used to make the dictator decision is the sum of both subjects' earnings and each earned either Rs. 200 (low) or Rs. 400 (high), there are four possible earning pair types: where both dictator and recipient earn equally high or low amounts [high-high (HH); low-low (LL)] and where both earn different amounts [(high-low (HL); low-high (LH)]. Furthermore, due to our interest in the effect of gender, the decision sheets also conveyed information about the matched subject's sex: either male or female. This was the first time that any explicit mention of gender was made during the experiment. Additionally, we also had an unknown gender case where there was no mention of partner's sex. The reason for having an unknown gender case is that it serves as a benchmark and allows us to identify differences in dictator behavior, if any, based solely on knowing the gender of the recipient. The dictator had to decide how much of the joint total earnings she wanted to keep or take for herself. All subjects made decisions as if they were the dictator. Then a coin toss determined whether the dictator decisions of room A ('heads') or room B ('tails') would be implemented. After submitting the decision sheets, all subjects were asked to fill in a short post-experiment questionnaire that sought some information on their background characteristics. They were also asked to explain briefly the reason for the allocation decision made by them. Finally, subjects were privately paid their earnings from the experiment in cash.

Subjects were recruited using flyers and notices posted throughout the campuses of University of Delhi and Jawaharlal Nehru University, Delhi. The study was conducted in November-December 2012 with 238 students enrolled in different disciplines. In all, we conducted 8 sessions that lasted about 65 min each. On average, there were 30 subjects in each session (minimum of 24, maximum of 34). The average payout was Rs. 400, which was inclusive of a fixed show-up fee of Rs. $100 .^{5}$

In terms of sample description, of the total 238 subjects, 132 are males $(55.46 \%)$ and the remaining 106 are females (44.54\%). Approximately $40 \%$ of subjects have prior experience of participating in economics experiments. Approximately $29 \%$ belong to high income family backgrounds (annual family income exceeding Rs. 0.5 million). On average, subjects have 1-2 siblings. $43 \%$ of subjects major in economics. Of the total 238 pairs, the distribution across the four earning pair types is as follows: 60 are $\mathrm{HH}, 54$ are LL, 62 are $\mathrm{HL}$, and 62 are $\mathrm{LH}^{6}$

\footnotetext{
${ }^{3}$ While it is debatable whether a logical reasoning test measures one's skill and ability rather than effort, our intention was to assign a task that enforced a feeling of entitlement. Since the subject pool was comprised of college students, a test of this type appeared to be contextually relevant. Oxoby and Spraggon (2008) and Heinz, Juranek, and Rau (2012) also make college students solve questions from the GMAT and GRE in the production phase.

${ }^{4}$ Since our objective was to test the effect of this relative earnings status on dictator decisions, giving information about the exact test scores may have led subjects to develop their own subjective notions of what 'high' and 'low' should be. This could be the case if they perceived the actual gap in the test score to not be large enough for their performance to be categorized as high or low relative to the recipient. However, this does not preclude the possibility that subjects' personal assessment of their own test performance affects their allocation decision.

5 At the time of conducting experiments, USD 1 was equal to Rs. 54.

${ }^{6}$ Distribution across the four pair types is not equal due to varying session sizes.
} 
Average shares appropriated by dictators

(a)

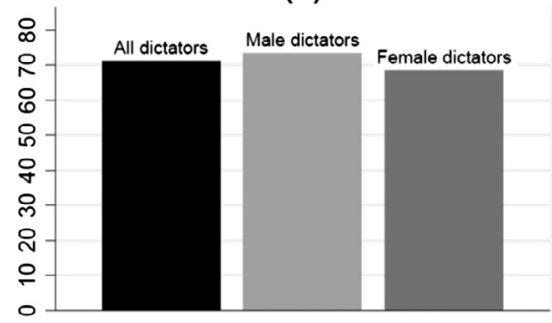

Male dictators' allocation by recipient gender

(c)

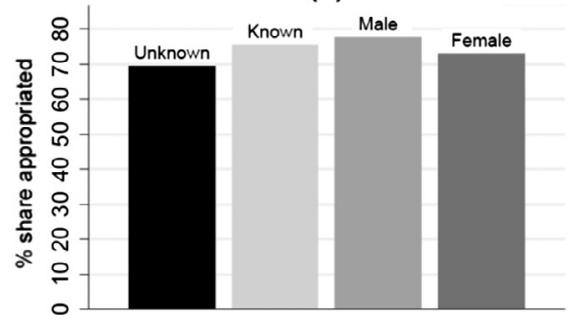

All dictators' allocations by recipient gender

(b)

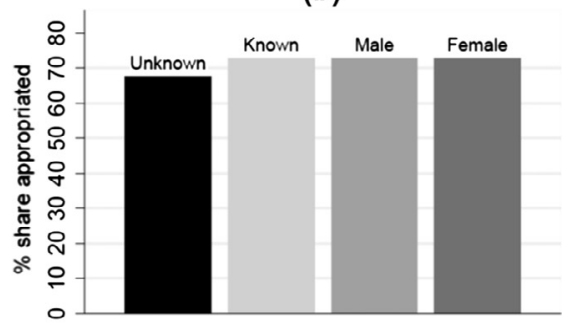

Female dictators' allocations by recipient gender

(d)

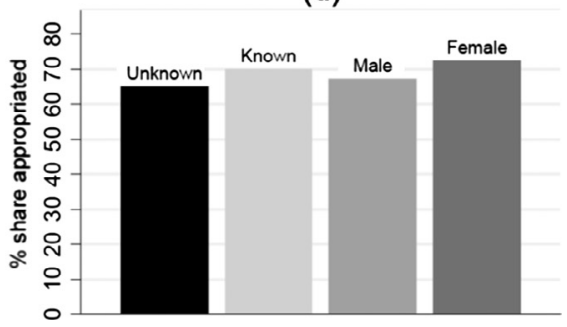

Fig. 2. Dictator allocations, by gender.

\section{Results}

\subsection{Descriptive statistics}

Overall, we find that dictators keep $71.2 \%$ of the total pie for themselves, thereby giving away $29 \%$ to their partners. This is in line with findings from other dictator games where the average amount given away is in the range of 20-30\% (Engel, 2011). Fig. 1 reports the distribution of dictator allocations. 29\% of dictators keep half the pie, 15\% keep two-thirds while $29 \%$ keep the full pie. ${ }^{7}$

Coming to gender differences reported in Fig. 2a, on average, male dictators keep 73.4\% and female dictators keep 68.5\% of the pie. This difference is not significant at conventional levels $(p$-value $=0.11){ }^{8}$ However, in multivariate regressions reported in the next section, the coefficient on the male dictator variable is highly significant once other factors have been controlled for. As Fig. 2b shows, when the recipient's gender is unknown, dictators keep $67.6 \%$ but when the gender is known (i.e., pooling male and female recipients), $72 \%$ is kept, suggesting that knowledge of the recipient's gender is associated with significantly greater appropriation ( $p$-value $=0.08$ ). However, conditional on knowing the specific gender of the recipient, both male and female dictators exhibit gender-neutrality by taking similar shares from male and female recipients (Fig. $2 \mathrm{c}$ and $\mathrm{d}$ ).

Examining whether dictators respond to inequality in earned endowments, we compare decisions under unequal earnings and identical earnings. In HH pairs, dictators keep 73.9\% of the pie whereas in HL pairs, the average share taken is $78.8 \%$. This difference is weakly significant ( $p$-value $=0.099$ ). In LL and LH pairs, dictators keep $72.1 \%$ and $60.2 \%$ respectively and the difference is highly significant $(p$-value $=0.003$ ). These comparisons indicate that even though on average, dictators in equal and unequal earnings pairs appropriate more than their earned proportion of the overall pie, they display some respect for merit - whether it is their own or that of the recipient - as the shares appropriated are correlated with relative earnings. Similar comparisons of decisions in unequal and equal earning pairs by dictator gender show statistically significant differences with the exception of male dictators appropriating similar shares in HH and HL pairs.

\subsection{Regression analysis: what explains dictator decisions?}

We estimate a multivariate linear regression model in order to isolate the effect of gender and relative earnings status on dictator decisions. The dependent variable is the percentage share of the pie appropriated by the dictator for herself. The primary variables of interest are the gender of dictator and recipient, and the earnings status which is measured by introducing dummy variables for high-high $(\mathrm{HH})$, high-low $(\mathrm{HL})$ and low-high $(\mathrm{LH})$ respectively, with the omitted category being low-low (LL) earning pairs. The other control variables we include are: (1) whether the subject has prior experience of participating in economics experiments since decisions may be influenced by previous exposure to such settings; (2) number of siblings since subjects who have been raised with brothers and sisters may be more likely to share; (3) whether the dictator

\footnotetext{
${ }^{7}$ Note that one of the reasons for getting a distribution of this type is due to the nature of the experiment and the payoff structure.

${ }^{8}$ Unless stated otherwise, reported $p$-values are for a Wilcoxon rank sum test.
} 
Table 1

Determinants of share appropriated.

\begin{tabular}{lll}
\hline & $($ Col. 1) & (Col. 2) \\
& Pooled sample & Pooled sample \\
\hline High-High (HH) & -6.533 & -6.603 \\
& $(5.439)$ & $(5.374)$ \\
High-Low (HL) & 2.563 & 2.640 \\
& $(4.465)$ & $(4.579)$ \\
Low-High (LH) & $-13.72^{* * *}$ & $-13.68^{* * *}$ \\
Male dictator & $(4.264)$ & $(4.281)$ \\
& $5.647^{* *}$ & $5.666^{* *}$ \\
Recipient gender: known & $(2.108)$ & $(2.098)$ \\
& $4.953^{*}$ & \\
Male recipient & $(2.704)$ & $5.400^{*}$ \\
Female recipient & & $(2.921)$ \\
High family income & & 4.474 \\
& & $(2.948)$ \\
Prior experience & $11.09^{* * *}$ & $11.16^{* * *}$ \\
Number of siblings & $(3.404)$ & $(3.418)$ \\
Economics student & 2.165 & 2.165 \\
& $(3.150)$ & $(3.138)$ \\
Constant & 0.005 & 0.0293 \\
& $(1.238)$ & $(1.250)$ \\
Observations & $11.53^{* *}$ & $11.50^{* *}$ \\
$R$-squared & $(3.971)$ & $(3.966)$ \\
\hline
\end{tabular}

Note: Dependent variable is percentage share appropriated. Session-room dummy variables included but not reported. Robust standard errors clustered at the session-room level are reported in parentheses. High-high: dictator earns Rs. 400, recipient earns Rs. 400; High-Low: dictator earns Rs. 400, recipient earns Rs. 200; Low-High: dictator earns Rs. 200, recipient earns Rs. 400. Omitted category is low-low. For recipient gender, the omitted category is recipient gender not known.

* Significant at $10 \%$.

** Significant at $5 \%$.

*** Significant at $1 \%$.

belongs to a high income background (annual family income exceeding Rs. 0.5 million). The correlation between income and sharing behavior could work in either direction. On the one hand, it is possible that subjects from affluent backgrounds are more generous since the stakes involved in the experiment are a 'drop in the ocean' and will not make them much better-off financially. On the other hand, subjects from richer backgrounds could have a greater sense of entitlement or privilege due to their background or they may place more consideration on merit and hard work which could lead to less generous behavior as dictators; and (4) whether the subject is an economics major since there is now ample evidence that students enrolled in economics programs tend to behave in a more selfish manner than non-economists in experiments (e.g., Carter \& Irons, 1991; Frank, Gilovich, \& Regan, 1993; Frey \& Meier, 2003; Marwell \& Ames, 1981). Session-room dummy variables are also included in the regressions and standard errors are robust and clustered at the session-room level.

In Table 1, we pool the sample of male and female dictators. Our results indicate that dictators are cognizant of earning inequalities between themselves and the paired recipient, especially when they are the relatively low earners as compared to the matched recipients. In the LH case, dictators keep 13.7 percentage points less than what they would when both are equally low earners and this difference is highly significant. In other words, low-earning dictators reward recipients who do better than them. On the other hand, when relatively high-earning dictators are paired with low-earning recipients (HL), they keep 2-3 percentage points more, but this difference is not significant. We also do not find dictator allocations in HH pairs to be significantly different from those in LL pairs. Male dictators keep significantly more (5.6 percentage points) than their female counterparts. As column 1 shows, knowing the gender identity of the recipient (which could be either male or female) results in significantly greater appropriation of 5 percentage points by dictators than when gender identity is unknown. In column 2, we further split up the recipient's known gender identity into male and female with the omitted category being unknown recipient gender. Upon doing so, we find that only if the recipient is male, there is a significantly greater share of 5.4 percentage points kept by the dictator. On the other hand, when the recipient is female, 4.5 percentage points more is appropriated but the difference is not statistically significant. In both columns of Table 1 , we find that dictators belonging to high-income backgrounds keep significantly more (11 percentage points) than those from lower income backgrounds. This is consistent with Carpenter, Verhoogen, and Burks (2005) and Banerjee and Chakravarty (2012) who also find allocations in dictator games to be negatively associated with family income. Using non-experimental data from the US 
Table 2

Determinants of share appropriated, disaggregated by dictator gender.

\begin{tabular}{lll}
\hline & $($ Col. 1) & (Col. 2) \\
& Male dictators & Female dictators \\
\hline High-High (HH) & -1.420 & $-16.94^{* *}$ \\
High-Low (HL) & $(6.338)$ & $(7.467)$ \\
& 5.725 & -0.913 \\
Low-High (LH) & $(7.765)$ & $(5.654)$ \\
& -8.879 & $-22.80^{* * *}$ \\
Male recipient & $(6.923)$ & $(5.512)$ \\
& $8.691^{* *}$ & 4.325 \\
Female recipient & $(3.952)$ & $(5.571)$ \\
& 4.917 & 10.01 \\
High family income & $(2.969)$ & $(5.783)$ \\
Prior experience & $15.91^{* *}$ & 4.191 \\
& $(5.747)$ & $(4.112)$ \\
Number of siblings & $6.627^{*}$ & $-10.48^{* *}$ \\
Economics student & $(3.381)$ & $(4.900)$ \\
& 1.088 & -2.166 \\
Constant & $(2.167)$ & $(1.463)$ \\
& $14.71^{* *}$ & 5.569 \\
Observations & $(6.614)$ & $(5.476)$ \\
$R$-squared & $54.39^{* * *}$ & $76.19^{* * *}$ \\
& $(9.295)$ & $(5.525)$ \\
\hline
\end{tabular}

Note: Dependent variable is percentage share appropriated. Session-room dummy variables included but not reported. Robust standard errors clustered at the session-room level are reported in parentheses. High-high: dictator earns Rs. 400, recipient earns Rs. 400; High-Low: dictator earns Rs. 400, recipient earns Rs. 200; Low-High: dictator earns Rs. 200, recipient earns Rs. 400. Omitted category is low-low. For recipient gender, the omitted category is recipient gender not known.

* Significant at $10 \%$

** Significant at $5 \%$.

*** Significant at $1 \%$.

General Social Survey and World Values Survey, Alesina and Giuliano (2011) also find that preferences for redistribution are weaker among the rich. Interestingly, and in accordance with other papers in the literature that find economics students to be more self-interested (e.g., Frey \& Meier, 2003; Marwell \& Ames, 1981), we find that students enrolled in economics programs keep 11.5 percentage points more than non-economics students.

In Table 2, we present results for sub-samples of male and female dictators and find that our results show heterogeneity by gender of the dictator. As is evident from column 1, primarily male dictators who take significantly more from male recipients than unknown recipients drive the overall recipient gender results reported in Table 1. On the other hand, as seen in column 2, female dictators do not seem to factor recipient gender into their appropriation decisions. This result is in contrast to Ben-Ner et al. (2004) who find that female dictators respond to recipient gender but male dictators do not. Among male dictators, we find that none of coefficients of earning status variables are significant. However, among females, earnings status plays an important role in determining allocations. As observed in the pooled sample in Table 1, relatively low-earning female dictators $(\mathrm{LH})$ appropriate 22.8 percentage points less than when low-earning females are paired with equally low earners. Also, when high-earning female dictators are matched with equally high-earning recipients (HH), they take almost 17 percentage points lesser than in the LL case. In terms of other variables, we find that results obtained for the pooled sample in Table 1 are being driven by males such that male dictators from affluent backgrounds keep more, and enrollment in an economics program leads to more appropriation by only the male dictators.

The finding that dictators appropriate more when recipient gender is known rather than unknown is an interesting and consistent result in our paper. However, this observed association runs in contrast to what is suggested in the literature. Experiments varying the level of information given to the dictator about the recipient typically find that more information either in the form of family names (Charness \& Gneezy, 2008), photographs (Burnham, 2003), visual identification (Bohnet \& Frey, 1999a) or verbal communication (Bohnet \& Frey, 1999b) leads to less self-regarding behavior and more generous offers as compared to cases where the dictator has no information.

\subsection{Exploring motivations for distribution}

While the previous section explored correlates of dictators' allocations, it does not allow us to disentangle the underlying competing motivations for their allocation choices. Following Cappelen et al. (2007), we can say something about the distributional preference at the individual level by comparing dictator decisions to the distribution of earned income from the task, and examine whether dictators invoke these preferences in a selective manner that advances their own interests. 


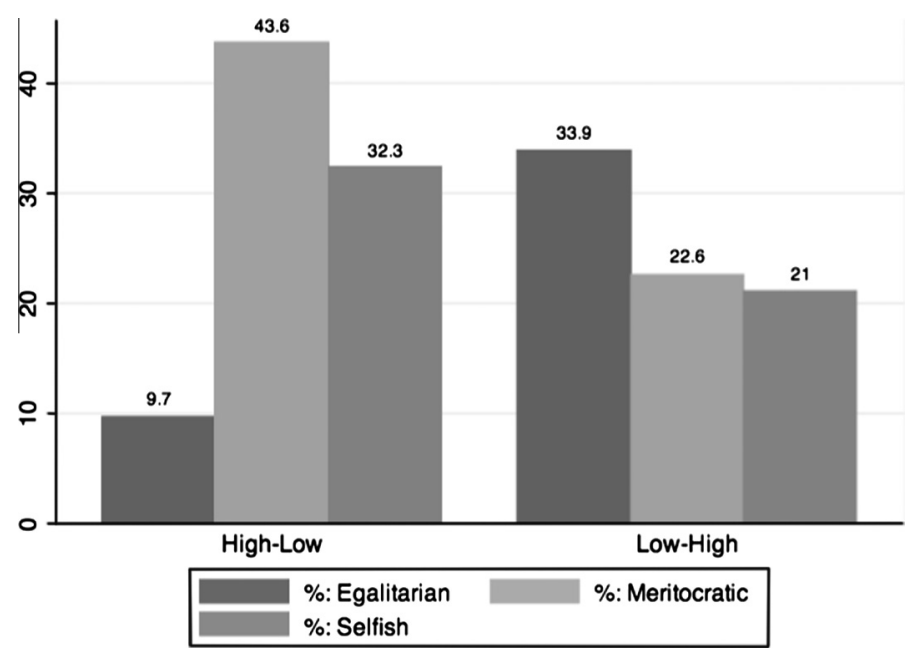

Fig. 3. Distributional preferences under unequal performance.

Hence, we categorize individuals as egalitarian, meritocratic or self-interested, and explain how these definitions are operationalized. A dictator is considered strictly egalitarian if she keeps exactly half of the overall pie. A dictator is said to be meritocratic if the share taken is equal to her earned proportion of the overall pie. ${ }^{9}$ Finally, we refer to a dictator as being self-interested if she keeps $100 \%$ of the pie for herself. By this criterion, 71 out of 238 dictators (29.8\%) make an egalitarian decision. In 85 out of 238 cases (35.7\%), dictators make a meritocratic decision and take as much as their earned share. Note that we cannot distinguish between egalitarian and meritocratic preferences when dictators in equal earning pairs (HH and LL) split the pie equally since in such cases an equal split could be indicative of egalitarian as well as meritocratic preferences. 68 out of 238 dictators (28.6\%) are self-interested. $24.4 \%$ of dictators do not split the pie according to one of these pure views of distributive justice but represent some form of 'unclassified' moral reasoning. Still, we find that $75 \%$ of our sample can be classified into these three categories.

To further examine whether dictators exploit a 'moral wriggle room', we compare the distribution of preferences when the dictators are the relatively high (HL) or low earners (LH) since that allows us to clearly identify the different categories. Fig. 3 shows that among dictators in HL pairs, 32.3\% are selfish, 9.7\% are egalitarian, and $43.6 \%$ make a meritocratic decision. On the other hand, among dictators in LH pairs, selfish, egalitarian and meritocratic decisions are made by $22.6 \%, 33.9 \%$ and $21 \%$ respectively. A chi-square test shows that a significantly greater proportion of dictators in LH pairs make an egalitarian decision ( $p$-value $<0.01$ ) and a significantly smaller proportion are meritocratic $(p$-value $=0.01)$ as compared to dictators in HL pairs. While a greater proportion of dictators in HL pairs are self-interested, the difference is not significant. The fact that there is a greater likelihood of resorting to an egalitarian (meritocratic) model when the dictator is a relatively low (high) earner indicates that dictators' practice situational ethics and reveal self-serving biases.

These patterns are also corroborated by qualitative responses offered by subjects in the post-experiment questionnaire that asked them to briefly state an open-ended reason for their decision regarding the split of the overall pie. While these responses may not be definitive proof of the intentions of subjects, they can still offer some interesting insights. After reading each response, we grouped the reasons into the same broad categories as above that are listed here with examples in parentheses:

(1) Egalitarian ("Since my partner and I put in the same effort even though we got different scores, I want to divide it 5050.").

(2) Merit-based ("I have taken 400 out of 800 since I deserve only that.").

(3) Self-interested ("I want to keep the larger share. So, I kept 3/4th for myself", and "I want to take as much as possible.")

(4) Miscellaneous (No response or incoherent answers).

As Table 3 shows, for the full sample (column 1), while $12.6 \%$ cite the egalitarian reason, $37.8 \%$ and $34 \%$ cite the meritocratic and selfish reasons respectively. The remaining $15.6 \%$ are of the miscellaneous type.

While disentangling preferences for egalitarianism and meritocracy is not possible in our case when dictators keep half the pie in equal earning pairs (HH and LL), we can analyze qualitative reasons offered by these subsets of dictators to gain some insight into their thinking. In both $\mathrm{HH}$ and LL pairs, substantially higher proportions (31-37\%) of dictators cite merit-

\footnotetext{
${ }^{9}$ We broadly identify merit-based preferences as our design does not allow us to distinguish between libertarian and liberal egalitarian preferences.
} 
Table 3

Distribution of stated reasons.

\begin{tabular}{|c|c|c|c|c|c|c|c|}
\hline Stated reason & $\begin{array}{l}\text { (Col. 1) } \\
\text { Total }\end{array}$ & $\begin{array}{l}\text { (Col. 2) } \\
\text { High-high }\end{array}$ & $\begin{array}{l}\text { (Col. 3) } \\
\text { Low-low }\end{array}$ & $\begin{array}{l}\text { (Col. 4) } \\
\text { High-low }\end{array}$ & $\begin{array}{l}\text { (Col. 5) } \\
\text { Low-high }\end{array}$ & $\begin{array}{l}\text { (Col. 6) } \\
\text { Male dictators }\end{array}$ & $\begin{array}{l}\text { (Col. 7) } \\
\text { Female dictators }\end{array}$ \\
\hline Egalitarian & $\begin{array}{l}12.61 \\
(30)\end{array}$ & $\begin{array}{l}3.33 \\
(2)\end{array}$ & $\begin{array}{l}5.56 \\
(3)\end{array}$ & $\begin{array}{l}9.68 \\
(6)\end{array}$ & $\begin{array}{l}30.65 \\
(19)\end{array}$ & $\begin{array}{l}12.12 \\
(16)\end{array}$ & $\begin{array}{l}13.21 \\
(14)\end{array}$ \\
\hline Merit-based & $\begin{array}{l}37.82 \\
(90)\end{array}$ & $\begin{array}{l}36.67 \\
(22)\end{array}$ & $\begin{array}{l}31.48 \\
(17)\end{array}$ & $\begin{array}{l}62.90 \\
(39)\end{array}$ & $\begin{array}{l}19.35 \\
(12)\end{array}$ & $\begin{array}{l}34.85 \\
(46)\end{array}$ & $\begin{array}{l}41.51 \\
(44)\end{array}$ \\
\hline Self-interested & $\begin{array}{l}34.03 \\
(81)\end{array}$ & $\begin{array}{l}55 \\
(33)\end{array}$ & $\begin{array}{l}33.33 \\
(18)\end{array}$ & $\begin{array}{l}19.35 \\
(12)\end{array}$ & $\begin{array}{l}29.03 \\
(18)\end{array}$ & $\begin{array}{l}40.15 \\
(53)\end{array}$ & $\begin{array}{l}26.42 \\
(28)\end{array}$ \\
\hline Miscellaneous & $\begin{array}{l}15.55 \\
(37)\end{array}$ & $\begin{array}{l}5 \\
(3)\end{array}$ & $\begin{array}{l}29.63 \\
(16)\end{array}$ & $\begin{array}{l}8.06 \\
(5)\end{array}$ & $\begin{array}{l}20.97 \\
(13)\end{array}$ & $\begin{array}{l}12.88 \\
(17)\end{array}$ & $\begin{array}{l}18.87 \\
(20)\end{array}$ \\
\hline
\end{tabular}

Note: Values represent percentage of subjects citing a reason. Numbers of observations in parentheses.

Table 4

Multinomial logit regressions exploring correlates of stated reasons.

\begin{tabular}{|c|c|c|c|}
\hline & $\begin{array}{l}\text { Col. } 1 \\
\text { Egalitarian reason }\end{array}$ & $\begin{array}{l}\text { Col. } 2 \\
\text { Merit-based reason }\end{array}$ & $\begin{array}{l}\text { Col. } 3 \\
\text { Selfish reason }\end{array}$ \\
\hline High-High (HH) & $\begin{array}{l}1.323 \\
(1.087)\end{array}$ & $\begin{array}{l}2.032^{* * *} \\
(0.707)\end{array}$ & $\begin{array}{l}2.138^{* * * *} \\
(0.694)\end{array}$ \\
\hline High-Low (HL) & $\begin{array}{l}1.974^{* *} \\
(0.887)\end{array}$ & $\begin{array}{l}2.146^{* * *} \\
(0.596)\end{array}$ & $\begin{array}{l}0.658 \\
(0.646)\end{array}$ \\
\hline Low-High (LH) & $\begin{array}{l}2.181^{* * * *} \\
(0.741)\end{array}$ & $\begin{array}{l}0.021 \\
(0.544)\end{array}$ & $\begin{array}{l}0.118 \\
(0.504)\end{array}$ \\
\hline Male dictator & $\begin{array}{l}0.034 \\
(0.509)\end{array}$ & $\begin{array}{l}-0.091 \\
(0.421)\end{array}$ & $\begin{array}{l}0.552 \\
(0.419)\end{array}$ \\
\hline Recipient gender: known & $\begin{array}{l}-0.742 \\
(0.583)\end{array}$ & $\begin{array}{l}-0.778^{*} \\
(0.457)\end{array}$ & $\begin{array}{l}0.328 \\
(0.472)\end{array}$ \\
\hline Constant & $\begin{array}{l}-1.271 \\
(0.754)\end{array}$ & $\begin{array}{l}0.519 \\
(0.475)\end{array}$ & $\begin{array}{l}-0.367 \\
(0.500)\end{array}$ \\
\hline Observations & 30 & 90 & 81 \\
\hline
\end{tabular}

Note: Robust standard errors reported in parentheses.

Total observations = 238. Base outcome group for the equation is miscellaneous reason. High-high: dictator earns Rs. 400, recipient earns Rs. 400; HighLow: dictator earns Rs. 400, recipient earns Rs. 200; Low-High: dictator earns Rs. 200, recipient earns Rs. 400. Omitted category is low-low. For recipient gender, the omitted category is recipient gender not known.

* Significant at $10 \%$

*** Significant at $5 \%$.

*** Significant at $1 \%$.

based reasons whereas only 3-5\% of them cite equality-based reasons, suggesting that most dictators acknowledge effort (columns 2 and 3).

Comparing responses of relatively high and low-earning dictators reveals patterns that are mostly consistent with quantitative results reported in Fig. 3. A significantly greater fraction of dictators in LH pairs cite egalitarian reasons ( $p$ value $<0.01$ ) and a significantly smaller fraction cite the merit reason ( $p$-value $<0.01$ ) as compared to dictators in HL pairs (columns 4 and 5). In terms of gender differences in stated reasons, we find significant differences between males and females citing the selfish reason with $41 \%$ of males stating so as compared to $26 \%$ of females (Chi-square test, $p$ value $=0.01$ ). For other reasons, gender differences are not significant.

In order to explore this more formally, we estimate multinomial logit regressions. The dependent variable refers to the categories of reasons offered by subjects for their decisions: egalitarian, merit-based, selfish, and miscellaneous (treated as base outcome), while the regressors are earning status dummy variables (HH, HL and LH) with the omitted category being LL; dictator gender dummy (male); and known recipient gender dummy variable. ${ }^{10}$ Results reported in Table 4 indicate that when both the dictator and recipient earn equally high amounts $(\mathrm{HH})$, they are more likely to offer merit-based as well as selfish reasons for their decision-making as compared to those in equally low-earning pairs. Relatively high-earning dictators (HL) are significantly more likely to offer egalitarian as well as merit-based reasons. On the other hand, relatively low-earning dictators (LH) are significantly more likely to state egalitarian reasons than when paired with an equally low earner. Ceteris paribus, we do not find any differences by dictator gender in the reasons offered. In terms of recipient gender, we find that when it is known, dictators are less likely to offer a merit-based reason, and this difference is weakly significant $(p$-value $=0.09)$.

\footnotetext{
${ }^{10}$ Note that due to large sample size requirements of the multinomial regression models due to the maximum likelihood estimation methods and estimation of multiple equations, we keep the model parsimonious and include only our key variables of interest.
} 


\section{Conclusion}

This paper employs a modified dictator game with production by both parties to study the effect of two broad factors: distributional preferences, and gender of dictator and recipient. In the first phase, subjects individually solve a logical reasoning test, the performance on which determines their earnings. In the second phase, dictators divide the pie, which is the sum of earnings of both, between themselves and the recipient, after learning about their own earning and the recipient's earnings and gender.

Our key results show that first, dictators display respect for merit, whether it is their own merit or that of the recipient, as attested to by the positive correlation between shares appropriated and earnings of dictators relative to recipients. Second, we observe some gender effects. Male dictators take more than their female counterparts. More is taken from known gender recipients and primarily driven by male dictators who take significantly more from male recipients than from unknown recipients. Further, only female dictators seem to take relative earning differences into account while making their decisions. Third, at the individual level, by comparing dictator decisions with the earned shares, we see that three-fourths of our sample can be classified as egalitarians, meritocrats or selfish. Dictators in unequal earning pairs invoke these fairness views in a situation-specific manner depending on their relative earnings and reveal self-serving biases. Specifically, relatively highearning dictators are more likely to arrive at a meritocratic decision and less likely to make an egalitarian decision than relatively low-earning dictators. Interestingly, these preference patterns are mostly consistent with qualitative reasons offered by dictators for their decision-making.

It is meaningful to state at this point that while the experiment was conducted in the context of a developing country, the sample was drawn from two elite universities that are comprised of a population that may not be representative of the larger Indian student population. Students from these colleges are therefore, likely to be more broad-minded toward issues of gender equality which can be a potential explanation for their gender-neutral attitudes toward recipients. It is worth noting that results may be different if one were to consider for instance, students in smaller towns or rural areas. It would be interesting to see in future research how fairness considerations are traded off across sexes among non-student population groups.

\section{Acknowledgements}

The experiment was funded by the University Grants Commission (UGC), New Delhi, India. Findings and conclusions offered are those of the author and do not reflect the views of the UGC. Srijita Das and Piyush Bhadani provided invaluable assistance in conducting the sessions. I thank Sujoy Chakravarty, Parikshit Ghosh, Ashwini Deshpande, Saurabh Singhal, Utteeyo Dasgupta, Deepti Goel and participants at Bay Area Behavioral and Experimental Economics Workshop 2013 and Symposium on Economics Experiments in Developing Countries 2013 for comments and feedback.

\section{Appendix A}

\section{A.1. Experiment instructions}

Hello and thank you for your participation. We are from Delhi University to conduct a study to analyze decision-making. Please pay close attention to the instructions and do not try to communicate with one another during the course of the study. For your participation, you will be paid a fixed fee of Rs. 100. You may also earn an additional amount of money, which will also be paid to you privately in cash at the end of the study. We will first make you do a task and then ask you to make some decisions. Both the performance on the task and the decisions that are made will determine earnings. Finally, there will be a short questionnaire.

In this session, there are people in 2 rooms who are participating at the same time. Each of you will be randomly paired with a different person who is in the other room. You will not be told who these people are either during or after the study. You will notice that there are other people in your room as well. You will not be paired with anyone in the same room as you. This is room A (B).

Your interactions and decisions will be anonymous. Each of you has been given an ID number that you will use throughout the study. Please enter the ID correctly where asked to do so. Your name will only be required at the end of the study when you get paid and will be required to sign a receipt.

Today we will start with a brief instruction period, where you will be given a complete description of the task and decision-making rules. After this you will do the actual task and make decisions that will determine your earnings. At the end of your decisions, while we prepare your payments, we will ask that you complete a short questionnaire.

The task at hand is a logical reasoning test, the rules of which are explained on the next page. After you finish doing the task, the question and answer sheets will be collected back from you and graded. While the test is being graded, we will request you to maintain silence. After the grading is completed, we will hand each one of you a decision form. In this form you will be told your performance on the task and the performance of the person you have been paired with. You will then decide how the joint total earnings will be split between you and the other person that you have been paired with. The person that you have been paired with will also receive the same decision form and will decide the split of joint total earnings 
between himself/herself and you. You will make your decision in writing. Once you have filled in the decision forms, we will collect them from you.

After this, based on a random draw, we will determine which person's decision in the pair is to be used to decide final earnings from the study. This means that either your decision or the decision of the person who has been paired with you will be used to determine final earnings for each of you. Based on a coin toss, we will decide whether decisions of room A or B are implemented. If the coin toss shows heads, room A decisions will be implemented and used for determining final earnings of both people in the pair. On the other hand, if the coin toss shows tails, room B decisions will be used to determine final earnings. In order to witness the outcome of the coin toss, one participant from each room will be randomly picked to go outside when the coin toss takes place. The participant will convey the outcome to the experimenter who will then announce the same to all the participants in the room.

Finally, you will be administered a short questionnaire that you will fill out yourselves.

While you complete the questionnaire, we will prepare your payments. After that, we will come to each of you individually and pay you and ask that you sign a receipt with your name, college name and amount received.

The task

We will now describe the task and the rules to you. Please pay attention because after this you will be made to do the task.

The task is a multiple-choice logical reasoning test with 20 questions. Each correct answer equals 1 point and each wrong answer will result in a loss of 0.25 points. You will not lose any points for not answering a question. On the basis of the points, the top $50 \%$ of performers in this room will earn Rs. 400 and the bottom $50 \%$ of performers will earn Rs. 200 . In the event that there is a conflict in determining clearly the top 50\% of the participants in the room due to multiple participants with similar number of points, the number of correct questions will be used to decide whether the participant should be in the top $50 \%$ or bottom $50 \%$.

You will have $20 \mathrm{~min}$ to solve the questions and fill in your answers in the answer sheet. Please make sure you circle only one option. If more than one option is circled, it will be considered as a wrong answer and you will lose 0.25 points. You may use the question paper for any rough work. Please do not do any rough work on the answer sheet. You will be informed when 5 min are left. Please make sure you stop when we announce that the time is over. Anyone who does not follow the rules will be disqualified and asked to leave.

If you have any questions at this time, then please raise your hand and we will come to you personally and answer it.

\section{A.2. Sample decision sheet (recipient gender is unknown)}

Please read the information carefully before making your decision.

You have to make a decision about allocating some money between yourself and a person from the other room. The paired participant will not know your identity during this study or later. Please remember that your response, which will determine the amount of money you earn from this study is confidential and your identity will not be known by anyone except the experimenter.

In the task, you earned Rs. and your paired participant earned Rs. Based on this, your joint total earnings are Rs.

You have to decide how much of the joint total earnings, that you and your paired participant earned, to keep for yourself. The decision is up to you. You can keep anything between Rs. 0 and the joint total of Rs.

Please enter below how much of the total earnings you want to keep for yourself.

Rs.

\section{A.3. Sample decision sheet (male recipient) ${ }^{11}$}

Please read the information carefully before making your decision.

You have to make a decision about allocating some money between yourself and a person from the other room. The paired participant will not know your identity during this study or later. Please remember that your response, which will determine the amount of money you earn from this study is confidential and your identity will not be known by anyone except the experimenter.

Your paired participant is a male. In the task, you earned Rs. and your paired participant earned Rs.

Based on this, your joint total earnings are Rs.

You have to decide how much of the joint total earnings, that you and your paired male participant earned, to keep for yourself. The decision is up to you. You can keep anything between Rs. 0 and the joint total of Rs.

Please enter below how much of the total earnings you want to keep for yourself.

Rs.

$\overline{11}$ The sample decision sheet (female recipient) just replaces 'male' with 'female'. 


\section{References}

Alesina, A., \& Giuliano, P. (2011). Preferences for redistribution. In J. Benhabib, A. Bisin, \& M. O. Jackson (Eds.), Handbook of social economics (pp. 93-131). Elsevier. Vol. 1.

Andreoni, J., \& Vesterlund, L. (2001). Which is the fair sex? Quarterly Journal of Economics, 116(1), $293-312$.

Banerjee, P., \& Chakravarty, S. (2012). The effect of minimal group framing in a dictator game experiment. <http://ssrn.com/abstract=2071006>.

Ben-Ner, A., Kong, F., \& Putterman, L. (2004). Share and share alike: Gender-pairing, personality, and cognitive ability as determinants of giving. Journal of Economic Psychology, 25(5), 581-589.

Bohnet, I., \& Frey, B. (1999a). Social distance and other-regarding behavior in dictator games: Comment. American Economic Review, 89(1), 335-340.

Bohnet, I., \& Frey, B. (1999b). The sound of silence in prisoner's dilemma and dictator games. Journal of Economic Behavior and Organization, 38(1), 43-58.

Burnham, T. C. (2003). Engineering altruism: A theoretical and experimental investigation of anonymity and gift giving. Journal of Economic Behavior and Organization, 50, 133-144.

Cadsby, C. B., Servetka, M., \& Song, F. (2010). Gender and generosity: Does degree of anonymity or group gender composition matter? Experimental Economics, 13(3), 299-308.

Cappelen, A. W., Hole, A. D., Sorensen, E. O., \& Tungodden, B. (2007). The pluralism of fairness ideals: An experimental approach. American Economic Review, 97(3), 818-827.

Cappelen, A. W., Moene, K. O., Sorensen, E. O., \& Tungodden, B. (2013). Needs versus entitlements: An international fairness experiment. Journal of the European Economic Association, 11(3), 574-598.

Cappelen, A. W., Sorensen, E. O., \& Tungodden, B. (2010). Responsibility for what? Fairness and individual responsibility. European Economic Review, 54, 429-441.

Carpenter, J., Verhoogen, E., \& Burks, S. (2005). The effect of stakes in distribution experiments. Economics Letters, 86(3), $393-398$.

Carter, J. R., \& Irons, M. D. (1991). Are economists different, and if so, why? Journal of Economic Perspectives, 5(2), $171-177$.

Charness, G., \& Gneezy, U. (2008). What's in a name? Anonymity and social distance in dictator and ultimatum games. Journal of Economic Behavior and Organization, 68, 29-35.

Croson, R., \& Gneezy, U. (2009). Gender differences in preferences. Journal of Economic Literature, 47(2), 1-27.

Dasgupta, U. (2011). Do procedures matter in fairness allocations? Experimental evidence in mixed gender pairings. Economics Bulletin, 31(1), 820-829.

Dufwenberg, M., \& Muren, A. (2006). Generosity, anonymity and gender. Journal of Economic Behavior and Organization, 61, 42-49.

Eckel, C., \& Grossman, P. (2008). Differences in the economic decisions of men and women: Experimental evidence. In C. Plott \& V. Smith (Eds.), Handbook of experimental economics results. New York: Elsevier.

Engel, C. (2011). Dictator games: A meta study. Experimental Economics, 14, 583-610.

Fehr, E., \& Schmidt, K. M. (1999). A theory of fairness, competition and co-operation. Quarterly Journal of Economics, 114(3), 817-868.

Frank, R. H., Gilovich, T., \& Regan, D. T. (1993). Does studying economics inhibit cooperation? Journal of Economic Perspectives, 7(2), $159-171$.

Frey, B. S., \& Meier, S. (2003). Are political economists selfish and indoctrinated? Evidence from a natural experiment. Economic Inquiry, 41(3), 448-462.

Frohlich, N., Oppenheimer, J., \& Kurki, A. (2004). Modeling other-regarding preferences and an experimental test. Public Choice, $119,91-117$.

Gong, B., Yan, H., \& Yang, C. (2015). Gender differences in the dictator experiment: Evidence from the matrilineal Mosuo and the patriarchal Yi. Experimental Economics, 18, 302-313.

Heinz, M., Juranek, S., \& Rau, H. A. (2012). Do women behave more reciprocally than men? Gender differences in real effort dictator games. Journal of Economic Behavior and Organization, 83(1), 105-110.

Konow, J. (1996). A positive theory of economic fairness. Journal of Economic Behavior and Organization, 31, $13-35$.

Konow, J. (2000). Fair shares: Accountability and cognitive dissonance in allocation decisions. American Economic Review, 90(4), 1072-1092.

Konow, J. (2003). Which is the fairest one of all? A positive analysis of justice theories. Journal of Economic Literature, XLI, 1188-1239.

Marwell, G., \& Ames, R. E. (1981). Economists free ride, does anyone else? Journal of Public Economics, 15, $295-310$.

Miller, L., \& Ubeda, P. (2012). Are women more sensitive to the decision-making context? Journal of Economic Behavior and Organization, 83(1), 98-104.

Niederle, M. (2014). Gender. NBER Working Paper No. 20788.

Nozick, R. (1974). Anarchy, state and Utopia. New York: Basic Books.

Oxoby, R. J., \& Spraggon, J. (2008). Mine and yours. Property rights in dictator games. Journal of Economic Behavior and Organization, 65, 703-713.

Rodriguez-Lara, I. (2015). An experimental study of gender differences in distributive justice. Spanish Journal of Economics and Finance, 38(106), 27-36.

Rodriguez-Lara, I., \& Moreno-Garrido, L. (2012). Self-interest and fairness: Self-serving choices of justice principles. Experimental Economics, 15, 158-175.

Ruffle, B. J. (1998). More is better, but fair is fair: Tipping in dictator and ultimatum games. Games and Economic Behavior, $23,247-265$. 